\title{
Rational number understanding: The big picture, not the essence
}

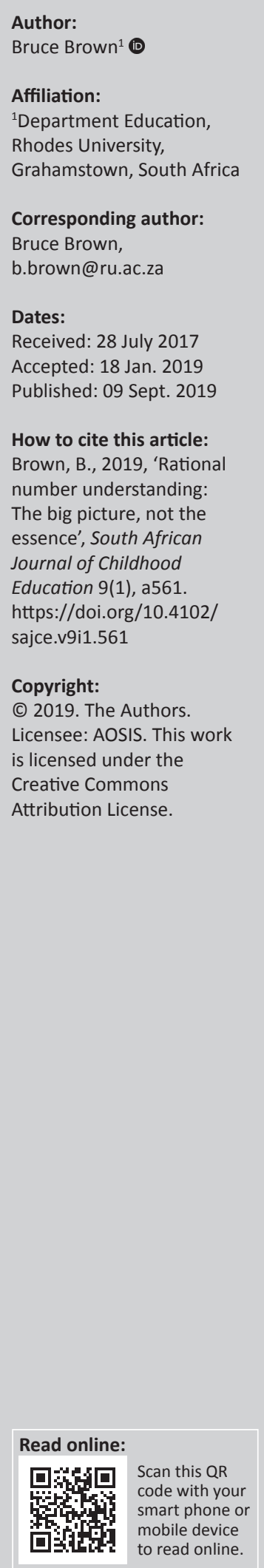

Background: The learning of rational numbers is a complex and difficult process that begins in the early grades. This teaching often focuses on the mastery of essential knowledge, including particular skills (e.g. using fractions to describe part-whole diagrams) and interpretations (e.g. sharing), which often results in an incomplete and inflexible understanding of these numbers.

Aim: This article proposes a holistic and relational perspective on rational number knowing and sense-making.

Setting: This possibility emerged through research into the learning of rational number concepts by Foundation Phase and Grade 4 children.

Methods: This research forms part of an ongoing, in-depth, exploratory research programme into the processes of learning rational numbers. Clinical interviews and classroom observations were the primary methods of data collection and an in-depth, constant comparative method of analysis was performed on the data.

Results: Thinking relevant to rational numbers was identified within four different perspectives through which children make sense of their interactions with the world, namely, social, instrumental, personal and symbolic sense-making.

Conclusion: The learning of rational numbers may be usefully seen as arising from the interrelation of multiple aspects of knowing and doing that develop as children balance these different ways of sense-making.

Keywords: Fraction Learning; Rational Number Learning; Sense-Making; Conceptual Development; Relational Understanding.

\section{Introduction}

The complexity of rational numbers and the difficulty of learning this number system in school are widely acknowledged (Kilpatrick, Swafford \& Swindell 2001). Research in this field has generated a great deal of results, spanning a wide range of issues. A number of organising principles for rational number learning have been proposed. These include viewing rational number learning as a process of conceptual change (Vanvakoussi \& Vosniadou 2004); building on the idea of 'magnitude' as a concept that unifies the whole, rational and real number systems (Siegler, Thompson \& Schneider 2011); the prime importance of relational understanding for rational numbers (Brown 2015; McMullen et al. 2015); and the rational number sub-constructs that constitute this conceptual field (Wright 2014). Each of the proposed principles provides insights into, and valuable recommendations for, some aspects of the learning process. However, because of the complexity of the desired learning, translating them into clear principles for organising the teaching and learning of this entire field has been proven to be difficult.

This article formulates and motivates a holistic, relational approach that views children's developing understanding of rational numbers as the capacity to engage flexibly with a complex system of relationships relevant to rational numbers, rather than the mastery of a particular, essential property or skill. This view balances four different perspectives on understanding, learning and using rational numbers. Viewing this process of relating between the child and his or her world from these different perspectives may provide a means for teachers to understand, introduce and maintain teaching and learning that allow flexible alignment with the complexity of rational number learning.

\section{Literature review}

\section{Perspectives on relational sense-making}

Four different perspectives on relational sense-making were found to provide useful insight into the complex process of rational number learning. These all hold that thinking enables action and 
that we construct our ways of thinking based on our interactions in the world - that is, our thinking and our relating with our world co-determine each other. Each of these perspectives has been developed in the context of sense-making in general, and the literature review will present this general development in more detail. The possibilities offered by relating these perspectives to children's developing rational number understanding will be explored in the remainder of this article.

Vygotsky (1978) states that, in a general sense, all higher mental functions have a social origin, namely, they first develop as social interactions before becoming appropriated and internalised as mental functions. In particular, children's development is fundamentally influenced by their mediated participation in goal-directed social activity. An important aspect of social interaction is the manner in which people are able to communicate their intentions and align with the intentions of others. In this way, we develop shared motives and goals, and we regulate our actions in order to satisfy these motives and achieve these goals (Leontev 1978; Veresov 2004). On internalisation, this contributes to a person's developing understanding of how the concepts and operations being learnt may be employed for the attainment of particular goals or motives (learning goal-directed causation). The term 'social sense-making' will be used to denote this element of sensemaking in social interaction, which forms one perspective on relational sense-making taken in this article.

Knowing that a particular way of interacting may contribute to achieving a certain goal is all very well, but we also need to be able to effectively act in order to achieve these goals. Vygotsky (1978) considers 'instrumental actions' in which a child acts, generally through the means of mediating tools, in order to achieve a practical goal. Piaget (1968; Flavell 1996) also considers the learning of such actions, particularly in relation to the physical world. Instrumental actions are also fundamental for theories of embodied cognition (Bergen \& Feldman 2008), which investigates how we act in ways that align with the constraints and affordances of the world, in order to achieve desired personal goals. In this interaction, multi-modal episodic models of our engagement are formed (Clark 1997), which enables the coordination of our embodied action. Such coordination allows the construction of appropriate relations (Richland, Stigler \& Holyoak 2012) that extend and develop the conceptualisation of the child. These include an understanding of actions and their consequences and how they may form chains of cause and effect (consequential, rather than goal-directed causation). This perspective of instrumental interaction will also be considered in this article and will be termed 'instrumental sense-making'.

Vygotsky (1986) also stresses the importance of words and representational forms (symbols), the way we attach meaning to them and the manner in which we may use these forms as mediating signs to influence children's thinking and learning. In this way, symbolising mathematical tools and processes (Tall 2008) also contributes to structuring children's thinking and to the formation and application of formalised mathematical conceptions. This formal view, oriented to the use of symbols in and about interactions, is the third perspective considered in this work, and it will be termed 'symbolic sense-making'.

Finally, children's appropriation and internalisation of experience is not a passive process, but involves both interpretation and generation of personal significance for the experience (Vygotsky 1978). The experience and its meaning are incorporated into the child's growing episodic memory (Moscovitch et al. 2016) of participation in interaction with his or her world. In this way, the child generates and maintains his or her sense of identity as a person in time and as a person who participates in particular mathematical practice (Boaler 2002) that incorporates rational numbers in engagement with the world. This will be the final perspective considered in this article and is termed 'personal sense-making'.

\section{Relational perspectives and research on rational number learning}

Much of the research on rational number learning has approached this question from the perspective of symbolic sense-making. A number of scholars have identified discontinuities between the formal structures of rational and whole numbers (Gelman \& Williams 1998; Ni \& Zhou 2005), which give rise to difficulties in children's learning of rational numbers, many of which remain evident in adults' rational number thinking. One such difficulty, and its effects on magnitude comparisons of rational numbers, has been termed by Vanvakoussi and Vosnaidou (2004) as the 'whole number bias', namely, responses when comparing the magnitudes of two rational numbers are influenced by the particular symbolic representation of these numbers, either as fractions or as decimals. For this reason, many researchers (McMullen et al. 2015; Ni \& Zhou 2005; Vanvakoussi \& Vosniadou 2004) have formulated initial rational number learning as an experience of conceptual change. Difficulties in understanding rational numbers that relate to differences in formal properties are an important area of research for conceptual change theorists (Siegler et al. 2013). The work of Siegler et al. (2011) challenges the view that these differences are fundamental for rational number learning, proposing instead that children should be encouraged to see rational numbers and whole numbers as one unitary formal system, united by the property of magnitude that may be symbolically represented on the number line - that is, this property and the use of the ordered number line should be the basis for teaching rational numbers.

Research focusing on instrumental sense-making has been active for many years and generally investigates operational schemata fundamental for rational number understanding, which are generated through experience of instrumental operations. Some examples are unitising, iteration, stretching and shrinking, partitioning and allocation. This work (Olive \& Steffe 2002; Steffe 2003; Tzur 2004) often involves in-depth analysis of learning interactions in order to describe the learning trajectories of particular learners. 
Relating these instrumental operations to the formal symbolic world, Kieren $(1976,1988)$ and Behr et al. (1983) enumerated five conceptual structures (sub-constructs) relating to rational numbers, namely, part-whole, measurement, quotient, operator and ratio. These are included by Wright (2014) in his hypothetical learning trajectory that may be applicable to a wider range of learners. The work of McMullen, HannulaSormunen and Lehtinen (2014) also includes both symbolic and instrumental sense-making. They studied the possible influence of children's spontaneous use of proportional quantitative relations to solve particular practical (instrumental) problems on their later learning of rational numbers. They found that the capacity of Grade 1 children to spontaneously focus on these relations in their solution to these problems showed some alignment with a measure of the same children's conceptual knowledge of fractions assessed three years later. A different study by Cortina, Visnovska and Zuniga (2014) investigated a teaching experiment in which a relational view of a unit fraction was developed by setting children's practical tasks of cutting straws into a specified unit fraction of a given stick. The children involved in this experiment developed a good understanding of the inverse relationship between the measure of a rational quantity and the size of the unit fraction used for the measurement.

A number of studies (Lamon 2007; Mack 2000; Noelting 1980) focusing on rational number teaching (particularly the teaching of young children) have emphasised the need to relate this teaching to children's lived experience. To do this, they have taken the perspective of social and personal sense-making. As an example, Noelting (1980) explored the development of ratios and proportional reasoning in the context of mixing juice. Moreover, the use of contextual questions related to the rational number sub-constructs was recommended by Lamon (2007) as a means of relating rational numbers to children's social world. A number of social activities included in this article draw on this recommendation.

\section{Research design and methods}

This article reports on research carried out in ongoing, qualitative, exploratory research programme investigating processes in early rational number thinking and learning. The aim of this research programme is to investigate the manner in which children make sense of concepts fundamental for the development of rational number understanding, based on both their prior experience and their school experience of rational number learning. The research explores the way children interact with task elements and with the interviewer, as they engage in activities related to the early learning of rational numbers. It is concerned with the nature of these interactions and the manner in which the children related these interactions with their prior experience, their task-related goals and their mathematical thinking. This research identified a number of emergent themes that involved different ways of relating, as well as the possible ways they influenced and were influenced by the way the children made sense of concepts fundamental for learning rational numbers. The perspective proposed in this article was formulated as an organising framework for these themes.

The programme incorporates a number of small-scale, indepth studies of particular issues, with the aim of developing deeper insights into this focal area and investigating possible implications for teaching. The results and perspective reported in this article were identified in three small-scale projects within this programme:

- clinical task-based interviews with four Grade R children (age 5), based on tasks related to the development of the rational comparison scheme;

- clinical task-based interviews with two Grade 3, Ruth and Jason (pseudonyms used to protect the anonymity of the children), investigating their engagement with everyday tasks related to rational number thinking; and

- participant observation of a number of fraction teaching lessons in two Grade 4 classes in a single school.

The data analysed in this project were generated by the researcher interacting with a child to explore and deepen his or her engagement with a specific task - again having the form of clinical, task-based interviews.

Interview data were audio-recorded and transcribed, and field notes of observations were maintained. Because only an audio recording was taken, the interviewer (identified as 'Int') included a verbal commentary, describing the actions of the child. This was indicated by the annotation 'describing' in the transcripts. In all projects, artefacts produced by children were collected and recorded for analysis. An in-depth constant comparative analysis was carried out to identify and formulate emerging themes that may provide insights into the manner in which the children made sense of the task and their responses. It is important to note that this research was not a teaching experiment and does not aim to develop a learning trajectory for rational numbers. Rather an insight was sought into the children's sense-making as they engaged in these microepisodes relating to the early learning of rational numbers, in order to generate insights that might be incorporated into teaching to deepen and strengthen the way children make sense of their developing rational number concepts.

Four ways of assigning meaning and significance (making sense) were identified as recurrent themes in this research. The in-depth qualitative analysis of this research suggests that flexible rational number understanding may arise from the coordination and relating of these different ways of making sense. The following section will present and discuss some of the inter-relations of these perspectives that were identified in the research and the manner in which they related to the children's making sense of rational numbers.

\section{Results: Making sense of rational numbers Personal and social sense-making}

Children engage readily in activities that are socially meaningful and personally significant to them. Such activities that embody ways of rational number thinking embed this 
thinking meaningfully into their social and personal world. In this way, rational number thinking takes a valid and useful place in children's social and personal worlds, and their ways of making sense in these worlds expand to include these mathematical concepts.

Ruth became engrossed in sharing playdough 'loaves of bread' between different model people she was given. She acted out her role of sharing bread between the models, talking to them as if they were real people in a real situation:

Ruth: One ... two ... three ... that one's a LITTLE bit too big ... Uh ... give it a little bit more ... that's one ... two ... three ... four. Four!

Int: Okay? You happy with that?

Ruth: Mhmmm! Oopsy!! Another piece for you ... another piece for you .... another piece for you ...

In acting to satisfy the social motive of distributing the bread in a manner which is fair to all, she brought the mathematical operation of equal subdivision appropriately into play in this social situation. Through her wholehearted participation in this role, she included this interaction into her episodic experience, contributing to her ongoing identity construction. Although not talking directly to the models, Jason also imaginatively engaged with them when sharing, talking about them by name:

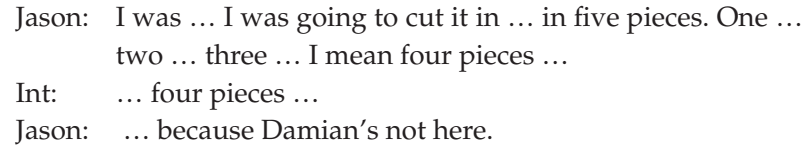

Being able to provide the same to each seemed to provide social and personal significance to the task. This was shown by the way he carefully re-cut the bread to achieve a more equitable sharing.

The importance of episodic memory for the recall of lived experience was notable in an activity related to baking loaves of bread. The children were shown two model baking tins (made of a matchbox and a halved matchbox), one of which had twice the capacity of the other. They were asked to divide some playdough between the two tins for baking. Ruth readily engaged with this task, describing what her mother did when baking. After relating the task to this meaningful social activity, she played it out in a personal engagement in this activity:

Ruth: And she also bakes ... bread sometimes.

Int: I've never baked bread. And how does she do it?

Ruth: She ... takes ... to make a cake she takes some flour and sugar and two eggs ... and ... She mixes them in a mixing bowl. And then she ... takes a ... batter and ... she puts it in ... a little tin like that ... (showing tin) ... and then she takes some plum or whatever kind of thing she's mixing ... and she ... um ... cuts it an' then she ... puts it in and then ... she puts icing or whatever she wants to put in an' then she puts it in the oven. Then it's nice ...

Jason also played himself into this task, even though his experience of baking seemed to have been much less, for he shared only that he had baked cupcakes with his mother.

\section{Personal, social and instrumental sense-making}

The social significance of sharing is clear, but without the property of being fair, sharing would lose much of this significance. Achieving fairness requires more than the social and personal interactions, it requires the capacity to act so that each person obtains an equal part. Here, the personal and social interactions need to be aligned with a practical, instrumental interaction regulated by the child to achieve a specific goal - that each person receives an equal amount.

In playing her sharing role, Ruth worked carefully to ensure that each person received a reasonably equal measure:

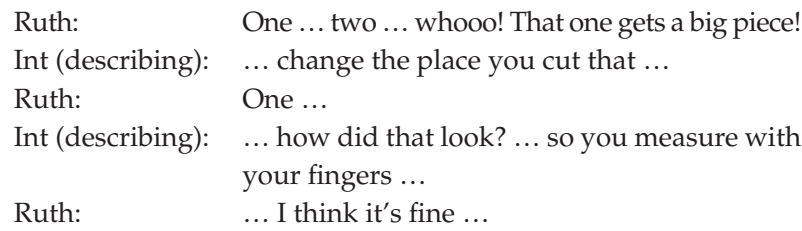

She was able to carry out this subdivision efficiently and so was able to devote most of her attention to playing out her social role. Jason understood the goal of equal sharing, but often needed substantial encouragement and a number of efforts before constructing an acceptable subdivision. When sharing three loaves between four children, he first cut two loaves into half, then:

$\begin{array}{ll}\text { Jason: } & \text { These two for them ... } \\ \text { Int (describing): } & \ldots \text { these two for them ... ? That looks good. } \\ \text { Jason: } & \ldots \text { it won't. } \\ \text { Int: } & \ldots \text { keep going. Don't stop. So that one for } \\ & \text { those two ... now you've got what!? You've } \\ & \text { got one loaf left over. } \\ \text { Jason: } & \begin{array}{l}\text { There ... I know! There ... There I must cut } \\ \text { this in four pieces. }\end{array}\end{array}$

In many instances, he immediately started cutting without considering the size of the pieces and so would end up with the wrong number of pieces or pieces of differing sizes. I would then give him new loaves to share and he would start again more carefully. When sharing between four, he also initially made four cuts, giving five shares and so started again. Near the end of this interaction, when given a replacement loaf, he seemed even to lose sight of the goal he was trying to achieve - asking the interviewer for a reminder or reassurance:

Int: $\quad \ldots$ four pieces. Which is good. Do you want to try with another loaf of bread (offering a replacement loaf to be cut)?

Jason: Okay. ... Must I ... must I ... make the ... four pieces in $\ldots$ in the whole loaf?

His confusion appeared to arise because of his need to focus on the practical details of achieving the equal subdivisions required for fair sharing. This indicates the importance of balancing the instrumental and social aspects of the task - too great a focus on the practicalities of carrying out the instrumental action could lead to a child losing touch with the social activity that gave meaning to his personal involvement in the task. 
Ruth efficiently divided up the dough into uneven amounts for baking in two matchbox 'tins' - one twice the size of the other. When the dough was presented as a long 'sausage', she cuts it carefully and quite accurately into two pieces in a 2:1 ratio. When 'balls' of dough were given:

Int: So he says, 'Fine. One of the little balls is good for the little tin'. How many little balls do you think he's gonna need for the big tin?

Ruth: I think ... two!

Jason also effectively divided the 'sausage' of bread dough between the two baking tins. He did this by immediately cutting the dough into slices of equal thickness and then organising the slices into two collections - one twice the size of the other. It should be noted that he did not fill the tins to do this and that the area covered by each collection was larger than the cross-sectional area of the respective tins. As he formed the collections, he continually looked from his collections to the tins and back - seeming to perform a visual comparison. When complete, the areas covered by the collections had the same ratio as the cross-sectional areas of the tins, suggesting that he had visually performed a proportional comparison. Both children seemed to tacitly use proportional comparison to carry out the instrumental task, indicating that they could access an embodied proportional comparison scheme - a scheme that provides an important foundation for rational number understanding.

The research with Grade R children included a task that they found difficult, but were able to complete with the support of the researcher. The children were shown pictures of collections of tricycles, which they recognised as such, from their personal experience at home and play school. They were first asked to count the number of tricycles, wheels and handles in each picture and all responded appropriately. After this, they were asked: 'how many wheels for every two handles in the picture?' The children appeared to find this question rather confusing. Ruth asked repeatedly for clarity, emphasising 'two' and identifying two handles, but finding it difficult to change her focus to then counting wheels:

Int: How many wheels are there for every two handles in the picture?

Ruth: One, two (pointing). Two handles? (Looking at interviewer.)

Int: Yes. So if you look at two handles... Do you see the two handles together?

Ruth: Yes. (Pointing out two handles in one tricycle)

Int: Then how many wheels are there for those two handles?

Ruth: (Looks again at picture, then indicating two handles on one tricycle with two fingers together and looking at the interviewer.) Two!

Int: Yes. Two handles. And wheels? Count the wheels?

Ruth: Three.

To answer this question, Ruth appeared to use the instrumental relationship that two handles were required to make one tricycle. Focusing carefully on the tricycle whose handles she had indicated, she identified the wheels and responded 'Three'. After counting wheels and handles in the next picture, the interviewer asked how many handles for three wheels. Again, indicating a single tricycle with its three wheels, she responded that there were two handles. The next question was how many handles for six wheels:

Ruth: (Leaning her chin on her hands and looking at the picture.) Six wheels.

Int: Six wheels would give you how many handles?

Ruth: (still looking) Two ... (fading away and looking for response)

Int: They would give you two? Show me six wheels?

Ruth: (Uses her finger to count six wheels of two tricycles.)

Int: Ok. So there are two 'whats' for those six wheels? (Child looks quietly with two fingers out pointing at the tricycles for which she had counted wheels.) (Interviewer prompts:) Two tricycles?

Ruth: (Slowly) Two tricycles.

Int: That's right. How many handles would go... with those six wheels?

Ruth: (Looking at the picture) Handles. (Looking at the interviewer.) Two (quickly correcting) Four...

Int: And now if you had six handles, how many wheels would you get?

Ruth: (Silent: Looking at the picture).

Int: (After some silence) Find six handles in the picture.

Ruth: (Looking carefully at the picture and counting with her fingers.) Nine.

It is clear that the children did not master proportional reasoning, but the data suggest a number of insights about the children's process of sense-making in relation to proportional reasoning in this task. Initially, the children appeared to find it difficult to make sense of the numerical relationship required. With some help and real effort, the children were then able to use the initial part quantity to identify a corresponding number of whole objects (tricycles) and thus complete the relationship by counting the number of the other desired part. Their focus on particular tricycles indicated that they noticed that the relationship between the handle count and the wheel count was because of the instrumental requirement of the number of handles and wheels to construct a tricycle. Once they had made sense of this instrumental relationship, they were able to use it to generate the mathematical relationship. Another reason for the difficulty may have been that this instrumental condition was not related to an appropriate social, or practical, activity, and thus the children were required to carry out instrumental sense-making with little support from either social or personal sense-making. Embedding this task into the social or practical context of building tricycles may have provided this support and thus made the task more accessible.

\section{Lack of symbolic sense-making}

We generate diagrams and symbols to represent these properties as well as mathematical operations on and relationships between them. Symbolic sense-making involves the use of these forms to represent, evoke and guide our thinking and interacting. But aligning instrumental and symbolic sense-making is by no means an easy task.

For instance, both Ruth and Jason were quite capable of using a tacit proportional comparison scheme to perform the 
instrumental task of allocating bread dough for baking. Yet, neither was able to represent these allocations symbolically. When asked to compare tin sizes or dough allocations, Ruth identified which was bigger or smaller and showed how the dough fit nicely into the tins. But she did not use numbers, doubling or halving to represent this 2:1 relationship. Similarly, Jason distributed the dough he had sliced in a manner proportional to the sizes of the tins. But when asked to compare these amounts, he merely identified which was bigger or smaller. When probed by the interviewer, he eventually quantified this comparison using the difference between his allocations - not a proportional comparison.

Prior to this research, both Jason and Ruth had been taught in class to write fractions to name part-whole diagrams. Thus, they had developed some capacity for symbolic sensemaking in relation to rational numbers. Yet, even with prompting, they did not use such fractions to describe the relationship between their allocations. Also, they were both familiar with doubling and halving whole numbers, yet did not use these formal operations to describe the relationship. Here, we can see a separation between the children's symbolic sense-making of rational numbers and their personal and operational sense-making, which was unhelpful in this situation where rational comparison was appropriate.

These mathematical concepts allowed the precise representation of this proportional comparison, which could have made the task of proportional distribution much simpler. Even though these symbols may have yielded powerful insights, this symbolic sense-making was not used in this task because the children did not relate them to this instrumental task in the personal and social situation of baking.

\section{Social, instrumental and symbolic sense-making}

The development of symbolic representations of rational numbers and proportion is necessary for a child's mathematical learning. Initially, such an understanding need not involve the use of the complex fraction or ratio notation. In the Grade R tricycle task, children were able to make lists (and tables) of the aligned quantities of tricycles, handles and wheels. These showed the manner in which these quantities varied together in a way that mirrored the proportion of wheels, handles and complete units. Note that tables show this relationship in a way similar to ratio notation.

The Grade 4 research included participant observation of a class where children completed worksheets with questions such as that shown in Figure 1.

As expected, most of the children named the quantity shown in $A$ as $6 / 9$ and that shown in B as $5 / 7$. But many wrote the comparison as: $6 / 9>5 / 7$, giving as reasons either 'because 6 is greater than $5^{\prime}$ or 'because 9 is greater than 7 '. In this case, the procedure used to create the symbolic form seems to have contributed to the children's misunderstanding of the fraction notation, by emphasising the two counting numbers used to

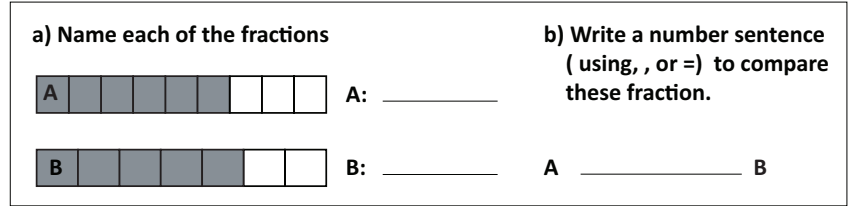

FIGURE 1: Fraction worksheet question.

form the fraction symbol at the expense of the relationship between them. In these diagrams, the wholes are the same size, and thus, the magnitude of the identified fraction is given by the size of the shaded part. Hence, a simple instrumental judgement of size would be sufficient to compare the proportional relationships described by the fractions. The teaching objective of the second question was to raise the children's awareness that a fraction described a rational number through the relation of the two numbers and that making sense of the fraction using either component as a simple count without reference to the other would not be appropriate. The diagram provided a grounding focus that was both appropriate to the fraction and provided simple perceptual cue for the comparison. In this task, most children used the diagram only to generate the naming fraction and then used one of the resulting counts to generate the incorrect comparison. To help a child focus on the relationship shown in the diagram and reduce their focus on the counts, the researcher informed one child that fractions were a new type of number and that the worksheet gave a picture showing how big each of these numbers was. On hearing this, the child exclaimed that $5 / 7$ was larger in the picture and immediately changed his comparison to correctly read $6 / 9<5 / 7$. He then went through the remainder of the worksheet and changed all the comparisons to be in line with the diagrams. A similar interaction followed with most of the other children who had initially inverted the comparison. This indicates the importance of social mediation to help the child focus on the instrumental conditions appropriate for interpreting his or her fraction symbols aligning social, instrumental and symbolic sense-making.

\section{Ethical considerations}

Ethical clearance was obtained from the Rhodes University Education Faculty Higher Degrees Committee (HDC) in July 2001 (S-FAC ED 2001.04.14 Document E). Data collected during the author's MEd research were used for analysis in this study.

\section{Conclusion}

\section{Understanding as synthesis, not analysis}

These investigations suggest that a number of different elements contribute to the manner in which children make sense of rational numbers and then draw on this sense-making to inform and regulate their interaction with the world. This sense-making and interaction may be viewed from four distinct, but complementary perspectives, which together constitute the child's growing experience and capacity. Taking this into account, a child's rational number understanding may be seen as not constituted by a single, essential property or capacity. Rather, this understanding forms a complex 
interrelated system of knowledge, capacities and dispositions. These synthesise the child's personal experience of social, instrumental and symbolic interactions that may be linked to the fundamental, relational nature of rational numbers. This complex system deepens, strengthens and builds coherence in the child's engagement in each of these worlds. Moreover, it is the structured unity of this system, not any one essential property, that allows it to be experienced, represented and communicated as a single domain of knowledge.

\section{Implications for teaching}

The most fundamental implication for teaching is the change in orientation towards the goals of rational number learning. A change from the mastery of part-whole counting to name quantities and of calculations involving fraction, decimal and percentage representations, possibly with a little problem solving thrown in for good measure. A change to mastery of the instrumental, social and symbolic means to interact with their world in personally meaningful ways that are enabled by rational number skills and concepts. Shortcomings of rational number learning may then be seen as less due to the lack of mastery of specific skills and more to narrowly compartmentalized experience that leads to the use of these skills in ways and in contexts in which they do not make sense.

The teacher's task will then involve moving between the global activity of balancing these different perspectives to ensure the child develops meaningful and mutually supportive relationships between these different perspectives and the local and technical activity of developing mastery of the knowledge and operational requirements appropriate to each perspective. Because current approaches are dominated by a symbolic focus, this will require teachers to improve their awareness of the social, instrumental and personal aspects of rational number knowledge and the manner in which they interrelate with each other and with the symbolic world. More important, it will involve learning to balance these aspects so that no perspective dominates at the expense of the others and that the child develops a coherent 'big picture' understanding of rational numbers, rather than the atomistic, unbalanced and partial understanding that currently is often the case.

Activity selection would then involve providing variation across the different perspectives and depth within each. Facilitation of these activities would encourage a deep and relational engagement both within and across the different perspectives. In addition to needing practice to develop the knowledge and skills needed for each perspective, children will need time and opportunities for discussion to enable a more holistic understanding to develop. Taking into account the current emphasis on the symbolic perspective, this will involve a reduced focus on the technical and symbolic aspects and an increase in the variation and interrelation of activities. This would build on the strengths of children, who show very real capabilities to solve social and instrumental problems that are meaningful to themselves, while the difficulties of this field of learning are generally presented by the technical and symbolic aspects of this understanding.

\section{Acknowledgements Competing interests}

The author declares that they have no financial or personal relationships that may have inappropriately influenced them in writing this article.

\section{Authors' contributions}

B.B. is the sole contributor to this article.

\section{Funding information}

This research received no specific grant from any funding agency in public, commercial or not for profit sectors.

\section{Data availability statement}

Data sharing is not applicable to this article as no new data were created or analysed in this study.

\section{Disclaimer}

The views and opinions expressed in this article are those of the authors and do not necessarily reflect the official policy or position of any affiliated agency of the authors.

\section{References}

Behr, M., Lesh, R., Post, T. \& Silver, E.A., 1983, 'Rational number concepts', in R. Lesh \& M. Landau (eds.), Acquisition of mathematical concepts and processes, pp. 91-126, Mamillan, New York, N.Y.

Bergen, B. \& Feldman, J., 2008, 'Embodied concept learning', in P. Calvo \& A. Gomila (eds.), Handbook of cognitive science: An embodied approach, pp. 313-332, Elsevier, Amsterdam.

Boaler, J., 2002, 'The development of disciplinary relationships: Knowledge, practice and identity in mathematics classrooms', For the Learning of Mathematics 22(1), 42-47.

Brown, B., 2015, 'The relational nature of rational numbers', Pythagoras 36(1), Art. \#273, 1-8. httsp://doi.org/10.4102/pythagoras.v36i1.273

Clark, A., 1997, Being there: Putting brain, body and world together again, MIT Press, Cambridge, MA.

Cortina, J.L., Visnovska, J. \& Zuniga, C., 2014, 'Unit fractions in the context of proportionality: Supporting students' reasoning about the inverse order relationship', Journal for Research in Mathematics Education 26, 79-99. https:// doi.org/10.1007/s13394-013-0112-5

Flavell, J.H., 1996, 'Piaget's legacy', Psychological Science 7(4), 200-203. https://doi. org/10.1111/j.1467-9280.1996.tb00359.x

Gelman, R. \& Williams, E., 1998, 'Enabling constraints for cognitive development and learning: Domain specificity and epigenesis', in D. Kuhn \& R. Siegler (eds.), Cognition, perception and language. Vol. 2. Handbook of child psychology, 5 th edn., pp. 575-630, Wiley, New York, N.Y.

Kieren, T.E., 1976, 'On the mathematical, cognitive, and instructional foundations of rational numbers', in R. Lesh (ed.), Number and measurement: Papers from a research workshop, pp. 101-144, ERIC.SMEAC, Columbus, OH.

Kieren, T.E., 1988, 'Personal knowledge of rational numbers: Its intuitive and formal development', in J. Hiebert \& M. Behr (eds.), Number concepts and operations in the middle grades, pp. 162-181, National Council of Teachers of Mathematics, Reston, VA.

Kilpatrick, J. Swafford, J. \& Swindell, B. (eds.), 2001, Adding it up: Helping children learn mathematics, National Academy Press, Washington, DC.

Lamon, S.J., 2007, 'Rational numbers and proportional reasoning', in F.K. Lester, Jr. (ed.), Second handbook of research on mathematics teaching and learning: A project of the national council of teachers of mathematics, pp. 629-667, Information Age Publishing, Charlotte, NC.

Leontev, A.N., 1978, Activity, consciousness and personality, Prentice Hall, Englewood Cliffs, NJ.

Mack, N.K., 2000, 'Long term effects of building on informal knowledge in a complex content domain: The case of multiplication of fractions', Journal of Mathematica Behaviour 19, 307-332. https://doi.org/10.1016/S0732-3123(00)00050-X

McMullen, J., Hannula-Sormunen, M. \& Lehtinen, E., 2014, 'Spontaneous focussing on quantitative relations in the development of children's fraction knowledge' Cognition and Instruction 32(2), 198-218. https://doi.org/10.1080/07370008.2014. 887085 
McMullen, J., Laakkonen, E., Hannula-Sormunen, M. \& Lehtinen, E., 2015, 'Modeling the developmental trajectories of rational number concepts', Learning and Instruction 37, 14-20. https://doi.org/10.1016/j.learninstruc. 2013.12.004

Moscovitch, M., Cabeza, R., Winocur, G. \& Nadel, L., 2016, 'Episodic memory and beyond: The hippocampus and Neocortex in transformation', Annual Review of Clinical Psychology 67, 105-134. https://doi.org/10.1146/annurev-psych-113011 143733

$\mathrm{Ni}$, Y. \& Zhou, Y.D. 2005, 'Teaching and learning fraction and rational numbers: The origins and implications of whole number bias', Educational Psychologist 40(1) 27-52. https://doi.org/10.1207/s15326985ep4001_3

Noelting, G., 1980, 'The development of proportional reasoning and the ratio concept: Part I - Differentiation of stages', Educational Studies in Mathematics 11, 217-253. https://doi.org/10.1007/BF00304357

Olive, J. \& Steffe, L.P., 2002, 'The construction of an iterative fractional scheme: The case of Joe', Journal of Mathematical Behavior 20, 413-437. https://doi. org/10.1016/S0732-3123(02)00086-X

Piaget, J., 1968, 'The mental development of the child', in J. Piaget (ed.), Six psychological studies. Vintage Books edition, pp. 3-76, Random House, New York, N.Y.

Richland, R.E, Stigler, J.W. \& Holyoak, K.J., 2012, 'Teaching the conceptual structure of mathematics', Educational Psychologist 47(3), 189-203. https://doi.org/10.1080/ 00461520.2012 .667065

Siegler, R.S., Fazio, L.K., Bailey, D.H. \& Zhou, X., 2013, 'Fractions: The new frontier fo theories of numerical development', Trends in Cognitive Sciences 17(1), 13-19. https://doi.org/10.1016/j.tics.2012.11.004
Siegler, R.S., Thompson, C.A. \& Schneider, N., 2011. 'An integrated theory of whole number and fractions development', Cognitive Psychology 62(4), 273-296. https://doi.org/10.1016/j.cogpsych.2011.03.001

Steffe, L.P., 2003, 'Fractional commensurate, composition, and adding schemes. Learning trajectories of Jason and Laura: Grade 5', Journal of Mathematical Behavior 22(3), 237-295. https://doi.org/10.1016/S0732-3123(03)00022-1

Tall, D., 2008, 'The transition to formal thinking in mathematics', Mathematics Education Research Journal 20(2), 5-24. https://doi.org/10.1007/BF03217474

Tzur, R., 2004, 'Teacher and students' joint production of a reversible fraction conception', Journal of Mathematical Behavior 23(1), 93-114. https://doi. org/10.1016/j.jmathb.2003.12.006

Vanvakoussi, X. \& Vosniadou, S., 2004, 'Understanding the structure of the set of rational numbers: A conceptual change approach', Learning and Instruction 14 453-467. https://doi.org/10.1016/j.learninstruc.2004.06.013

Veresov, N., 2004, 'Zone of proximal development (ZPD): The hidden dimension?' in A.L. Ostern \& R.H. Ylikallio (eds.), Language as culture tensions in time and space, Vol. 1, pp. 13-30, ABO Akademi, Vasa.

Vygotsky, L.S., 1978, Mind in society: The development of higher psychological processes, transl. eds. M. Cole, V. John-Steiner, S. Scribner \& E. Souberman, Harvard University Press, Cambridge, MA.

Vygotsky, L., 1986, Thought and language, transl. eds. A. Kozulin, MIT Press, Cambridge, MA.

Wright, V., 2014, 'Towards a hypothetical learning trajectory for rational number', Mathematics Education Research Journal 26(3), 635-657. https://doi.org/10. 1007/s13394-014-0117-8 